\title{
La satisfacción del derecho a la justicia en el marco del proceso de paz colombiano. Una mirada a la evolución en materia de responsabilidad penal en el contexto de un proceso de paz y de los actuales estándares internacionales ${ }^{\star}$
}

The Satisfaction of the Right of Justice under the Colombian Peace Process. A Look at Developments in the Field of Criminal Responsibility in the Context of a Peace Process and Current International Standards

A satisfação do direito à justiça no marco do processo de paz colombiano. Uma mirada à evolução em matéria de responsabilidade penal no contexto de um processo de paz e dos atuais standards internacionais

\author{
BEATRIZ EUGENIA SUÁREZ LÓPEZ ${ }^{\star *}$ \\ Universidad Jorge Tadeo Lozano
}

FELIPE JARAMILLO RUIZ ${ }^{\star \star \star}$

Universidad Sergio Arboleda

FECHA DE RECEPCIÓN: 13 DE ENERO DE 2014 • FECHA DE ACEPTACIÓN: 5 DE MAYO DE 2014

Doi: dx.doi.org/10.12804/esj 16.02.2014.02

Para citar este artículo: Suárez L., B. E., G Jaramillo, R. F. (2014). La satisfacción del derecho a la justicia en el marco del proceso de paz colombiano. Una mirada a la evolución en materia de responsabilidad penal en el contexto de un proceso de paz y de los actuales estándares internacionales. Estudios Socio-Jurídicos, 16(2), 61-88. Doi: dx.doi.org/10.12804/esj 16.02.2014.02

* El presente artículo es un avance de la investigación: “Experiencias de paz: lecciones aprendidas para Colombia", financiada por la Universidad de Bogotá Jorge Tadeo Lozano.

** Profesora asociada I de la Universidad Jorge Tadeo Lozano (Bogotá D.C., Colombia). Abogada y especialista en Ciencias Penales y Criminológicas de la Universidad Externado de Colombia; magíster en Derecho con énfasis en Derecho Penal de la Universidad Alcalá de Henares (España). Autora de varios artículos académicos. Correo electrónico: beatrize.suarezl@utadeo.edu.co

*** Profesor de tiempo completo de la Universidad Sergio Arboleda (Bogotá D.C., Colombia). Profesional en Relaciones Internacionales de la Universidad Jorge Tadeo Lozano; magíster en Democracia y Transformaciones Globales de la Universidad de Helsinki (Finlandia); estudiante de último semestre de Derecho de la Universidad Jorge Tadeo Lozano. Correo electrónico: felipe.jaramillo@ usa.edu.co 


\section{RESUMEN}

El artículo analiza los acuerdos de paz que se dieron en Colombia durante las décadas de los ochenta y noventa, con el fin de contrastar dichas experiencias con el actual proceso de negociación que se está llevando a cabo en La Habana con las FARC. En particular, se estudia cómo en el marco de estos procesos de paz se abordó el derecho de las víctimas a la justicia y la concesión de amnistías e indultos a los miembros de los grupos armados ilegales. A la luz de los acuerdos mencionados, se discuten los alcances del Acto Legislativo 1 de 2012 en el proceso de paz y, sobre todo, las implicaciones en materia de responsabilidad internacional no solo para el Estado colombiano, sino también para los perpetradores de delitos de trascendencia internacional.

Palabras clave: proceso de paz, Corte Penal Internacional, derecho a la justicia, derechos de las víctimas, Marco Jurídico para la Paz, justicia transicional.

\section{ABSTRACT}

With the purpose of comparing the peace agreements that were carried out in Colombia during the decades of the 80 s and 90 s and the current negotiation process that is taking place in Havana with the FARC, the article identifies the lessons of the peace processes selected and discusses their relevance to the negotiation in progress. In particular, the article explicates how the right to justice of the victims, and the amnesties and pardons to members of illegal armed groups, were addressed in the past. Furthermore, the article examines the Legislative Act 1 of 2012, which establishes the so-called 'Legal Framework for Peace'. Thus, it highlights the possible consequences in regards to international responsibility of the Colombian State and of the perpetrators of international crimes.

Key words: peace process, International Criminal Court, the right to justice, victims' rights, legal framework for peace, transitional justice.

\section{RESUMO}

O artigo analisa os acordos de paz que se deram na Colômbia durante as décadas dos anos oitenta e noventa, com o fim de contrastar ditas experiências com o atual processo de negociação que está se levando a cabo em La Habana com as FARC. Em particular, estuda-se como no marco destes processos de paz se abordou o direito das vítimas à justiça e a concessão de anistias e indultos aos membros dos grupos armados ilegais. À luz dos acordos mencionados, discutem-se os alcances do Ato Legislativo No. 01 de 2012 no processo de paz e, especialmente, as implicações em matéria de responsabilidade internacional não só para o Estado colombiano, mas também para os perpetradores de delitos de transcendência internacional.

Palavras-chave: Processo de paz, Corte Penal Internacional, direito à justiça, direitos das vítimas, marco jurídico para a paz, justiça transicional. 


\section{Introducción}

En sociedades que han padecido largos conflictos armados, los procesos de paz representan una luz de esperanza, una oportunidad para poner fin a la guerra. Sin embargo, las expectativas generadas por los acuerdos de paz en su mayoría se enfrentan con la decepción del fracaso. Según Barbara F. Walter (1999), en más de la mitad de los casos (53\%) de las 41 negociaciones formales destinadas a poner fin a los conflictos armados que se dieron entre 1940 y 1990, los adversarios que firmaron el acuerdo de paz retomaron la guerra. Básicamente, los acuerdos fueron treguas efimeras que no tardaron en derrumbarse y transformarse en nuevos ciclos de violencia. Al examinar el porqué de los resultados tan desfavorables, la autora concluye que el mayor desafío para alcanzar un acuerdo exitoso es convencer a los combatientes de dejar las armas, a sabiendas de que dicha decisión incrementa su vulnerabilidad y limita su capacidad de garantizar el cumplimiento de los términos suscritos en el pacto (Walter, 1999, p. 127). Por esta razón, para que un acuerdo de paz sea exitoso, su construcción debe forjar la confianza suficiente para que los combatientes renuncien a la lucha armada como una estrategia de promoción de sus objetivos. ${ }^{1}$

En los acuerdos de paz, la justicia se enlaza a la confianza de una manera compleja y delicada. Primero, la falta de justicia puede suscitar sentimientos de venganza y comportamientos sociales que minan la confianza entre las partes. ${ }^{2}$ Fundamentalmente, la sensación de impunidad tiene la capacidad de originar actuaciones de segregación y discriminación que dificultan la reintegración de los combatientes a la sociedad civil. Segundo, la presión para el cumplimiento de estándares elevados de justicia puede causar incertidumbre en las partes sobre la ejecución cabal de las concesiones plasmadas en los acuerdos negociados. Como consecuencia, las demandas de

1 John Campbell (1976) analiza de manera detallada qué elementos son necesarios para lograr una negociación exitosa. Por su parte, Caroline Hartzell (2006), en su artículo "Structuring the peace: negotiated settlements and the construction of conflict management institutions", discute a profundidad las instituciones que se requieren para avanzar en la construcción de paz. Ver también: Brandt et al. (2008).

2 David Mendeloff (2009) cuestiona la efectividad de las comisiones de la verdad en la satisfacción de los derechos a las víctimas. Sin embargo, diversos autores hacen hincapié en la importancia de la justicia como un elemento fundamental en la construcción de paz. En general, la concesión de amnistías e indultos a los perpetradores de delitos de trascendencia internacional fomenta la inconformidad de las víctimas ante un posible acuerdo de paz (Lira, 2010; Laplante, 2008). 
justicia fomentan en los combatientes la sospecha de que, al dejar las armas y encontrarse vulnerables, se les va a perseguir y juzgar por acciones que habían sido cobijadas por los indultos y amnistías negociados en el acuerdo. Ante la tensión descrita, cabe preguntarse ¿cómo hacer para que la justicia sea un instrumento de confianza y no un obstáculo para esta?

Uno de los temas recurrentes en los debates sobre el proceso de paz que se está llevando a cabo en La Habana gira en torno a las ataduras jurídicas que nacen a partir de la ratificación del Estatuto de Roma por el Estado colombiano. Algunos sectores políticos argumentan que el Estatuto, al abrir la puerta de ingreso para la Corte Penal Internacional (CPI) y al admitir su jurisdicción, limita el margen de maniobra del gobierno en la mesa de negociación con las FARC. Así, defienden que cualquier pacto que conceda beneficios que se asemejen a la amnistía o al indulto y que cubran a aquellos combatientes que hayan perpetrado crímenes graves de trascendencia para la comunidad internacional (genocidio, lesa humanidad, de guerra o de agresión) será inválido y abrirá el paso para el inicio de procesos de responsabilidad internacional individual ante la CPI.

La discusión en torno a la CPI es un reflejo de cómo la justicia carga en su interior uno de los dilemas más contundentes que toda sociedad en un proceso de paz debe abordar con detenimiento. Más allá de las dificultades legales, el tema de la justicia se ata al futuro acuerdo de paz como uno de los elementos esenciales que determinará si es posible la consolidación de estructuras de confianza que propendan por evitar una recaída a la violencia. En este sentido, el concepto de justicia no se limita únicamente a restricciones normativas, sino que encarna los cimientos básicos que permiten que las heridas infligidas durante el conflicto tengan la vocación de sanar. De lo contrario, si lo que prevalece es el sentimiento generalizado de injusticia, las probabilidades de que el posconflicto se torne simplemente un cese temporal de hostilidades aumentan drásticamente. ${ }^{3}$

El presente artículo de investigación científica es un primer resultado del proyecto "Experiencias de paz: lecciones aprendidas para Colombia" de la Facultad de Ciencias Sociales de la Universidad de Bogotá Jorge Tadeo Lozano. El propósito consiste en exponer los hallazgos iniciales del pro-

3 Elisabeth Porter argumenta: "The urge toward vengeance is more likely when there is a feeling that justice is being denied. Such a feeling may arise in places where amnesty occurs" (Porter, 2007, p. 122). Ver también: Hamber (2003). 
yecto, cuyo objetivo es identificar las principales lecciones de construcción de paz -tanto nacionales como internacionales- que se pueden aplicar al actual proceso de negociación con las FARC. Con base en esta propuesta, el artículo analiza los acuerdos de paz que se dieron en Colombia durante las décadas de los ochenta y noventa, con el fin de contrastar dichas experiencias con el actual proceso de negociación que se está llevando a cabo en La Habana con las FARC. En particular, se estudia cómo en el marco de estos procesos de paz se abordó el derecho de las víctimas a la justicia y la concesión de amnistías e indultos a los miembros de los grupos armados ilegales. Adicionalmente, a la luz de los acuerdos mencionados, se discuten los alcances del Acto Legislativo 1 de 2012 -que establece el llamado Marco Jurídico para la Paz y mediante el cual se reformó la Constitución Política de Colombia - en el proceso de paz y, sobre todo, las implicaciones en materia de responsabilidad internacional no solo para el Estado colombiano, sino también para aquellos que pudiesen eventualmente responder ante la CPI.

\section{Metodología}

En términos metodológicos, la investigación parte de una aproximación pluridisciplinaria a las ciencias sociales. Los múltiples casos de estudio son analizados desde una óptica transversal a las ciencias sociales, motivo por el cual se hace uso de fuentes primarias y secundarias, tanto académicas como prácticas, de diversas disciplinas. Así, la investigación se nutre del conocimiento de la ciencia política, las relaciones internacionales, el derecho y la historia, entre otros, con el fin de desarrollar un análisis comparativo que aporte a las discusiones académicas sobre la construcción de paz en Colombia.

Son dos las aproximaciones metodológicas que permitieron el desarrollo de la investigación. Primero, se recurrió a una variedad de documentos académicos e investigativos sobre los acuerdos de paz que se dieron en Colombia durante la década de los ochenta y noventa. Una vez realizado el estado del arte, se hizo un barrido normativo por medio del cual se esclareció el marco legal regulatorio de los acuerdos objeto de estudio. En especial, se investigó cómo se procedió con la concesión de amnistías e indultos y cómo se garantizó el derecho de las víctimas a la verdad. 
Segundo, se analizaron los principales problemas jurídicos que tendría que soslayar el futuro acuerdo con las FARC en caso de que se replicaran las pautas de los acuerdos de paz antes mencionados. Con base en el estudio del Acto Legislativo 1 de 2012 y en el análisis de los pronunciamientos de la Corte Interamericana de Derechos Humanos (CIDH) y de la CPI, se discute cómo el contexto normativo actual es sustancialmente diferente al de las décadas pasadas.

\section{El derecho a la justicia a lo largo de los procesos de paz en Colombia}

En la búsqueda por la construcción de paz en Colombia, en las décadas de los ochenta y noventa, dos modelos predominaron en la elaboración de las políticas del gobierno nacional (Pardo, 2002). El primero se implementó durante la administración de Belisario Betancur (1982-1986). El segundo se promovió inicialmente durante la administración de Virgilio Barco (19861990) y continuó, con algunas modificaciones, durante la administración de Cesar Gaviria (1990-1994). Cada modelo concebía la construcción de la paz desde una óptica específica, motivo por el cual sus postulados y propuestas buscaron el fin del conflicto armado desde las particularidades de su visión. No obstante, a pesar de sus diferencias, ambos modelos compartieron un sinnúmero de fallas sustanciales. A continuación, se discutirán las ideas básicas que defendieron los dos enfoques de paz, para luego analizar cómo estos impactaron la elaboración del marco jurídico de los procesos de desmovilización, desarme y reintegración.

\subsection{El modelo voluntarista}

La administración de Belisario Betancur introdujo una orientación voluntarista a la construcción de paz. Este modelo comprendía el conflicto armado en términos de contradicciones históricas y, por lo tanto, buscaba remediarlas. A través del reconocimiento de las condiciones objetivas que alimentaban la formación de grupos guerrilleros, el gobierno impulsó y desarrolló proyectos que pretendieron atender, remediar y subsanar aquellas problemáticas que según los grupos insurgentes justificaban la lucha armada. 
El reconocimiento de los factores que engendraban la violencia tenía como propósito la dejación voluntaria de las armas por parte de los grupos guerrilleros. Por lo tanto, se partía de la primicia de que la corrección de los factores objetivos conllevaría automáticamente a conseguir el desarme, la desmovilización y la reintegración de los grupos armados al margen de la ley.

Marc W. Chernick (1996, p. 5) cuenta cómo en la administración de Betancur se cambió la manera en la que se buscaba construir la paz. Según el autor:

El común de la gente piensa que los intentos de paz del presidente Betancur fracasaron. Sin embargo, hay que reconocer que en su gobierno hubo un cambio importante en la dirección del discurso político del país. Se introdujeron dos elementos al discurso político nacional: el primero reconoció que la oposición armada es un actor político y que es necesario abrir un diálogo con ella. El segundo planteó que Colombia, como otros países en América Latina en esta época, también requería un proceso de apertura democrática.

Los cambios señalados por el autor no fueron contundentes. ${ }^{4}$ Es posible evidenciar que el enfoque voluntarista propagado por el presidente Betancur contenía serias deficiencias (Fernández, García-Durán y Sarmiento, 2004). Primero, el modelo pasaba por alto las controversias que se creaban a raíz de la distribución del poder político. Consecuentemente, al centrarse en el voluntarismo de los grupos al margen de la ley para alcanzar la paz, el modelo carecía de una visión holística que capturara el tinte político de la lucha armada. Segundo, se mostró insuficiente para la formación y consolidación de espacios de participación democrática (Calvo, 2008, pp. 144-145). Por consiguiente, no se desarrollaron de manera clara, estructurada y sistemática espacios que dieran a los grupos armados posibilidades concretas de participación política, lo que forjó un vacío institucional que dificultó la formación de la confianza suficiente para que los grupos al margen de la ley creyeran que, en un escenario de posconflicto, ellos podrían propender por la persecución de sus intereses sin la necesidad de las armas.

4 Un informe de Amnistía Internacional de 1988 establece que: "La mayoría de los 500 presos políticos liberados por la amnistía de 1982 fueron asesinados, desaparecidos o forzados al exilio" (Calvo, 2008, p. 144). 
En una entrevista realizada en 1986, Antonio Navarro Wolff, miembro entonces del Mando Central del M-19, describió el diseño del proceso de paz del presidente Betancur de la siguiente manera:

"Ese diseño, que tenía como objetivo el desarme de la guerrilla, implicaba un modelo parecido al de la paz en Venezuela, o sea, a cambio de la legalización de los guerrilleros estos debían deponer las armas de manera permanente"; y agregó: "El derecho a salir a las plazas públicas sin que lo mataran a uno o sin que lo metieran preso no era suficiente para deponer las armas, que en el país han sido el instrumento más eficaz para hacer política en los últimos años" (Jiménez, 1989, p. 89).

Nuevamente, de las declaraciones de Navarro Wolff, es posible extraer algunas falencias del modelo voluntarista que puso en funcionamiento el gobierno de Betancur. No solo carecía de verdaderos incentivos para que los grupos guerrilleros depusieran las armas, sino que rehusaba ver el contenido político de la lucha armada. Por consiguiente, no atendía el mensaje que llevaba de manera implícita la guerra: la violencia como una forma de hacer política ante lo que se percibía como un sistema democrático de fachada que contenía múltiples debilidades institucionales.

Las propuestas para avanzar hacia el fin de la lucha armada se materializaron como concesiones unilaterales a los grupos armados, como incentivos para su desmovilización. No se buscó la participación de la sociedad civil para la elaboración de los acuerdos de paz (Pardo, 2002), lo que mantuvo al margen de la discusión a los demás actores que por motivos históricos se habían visto envueltos en la lucha armada entre el Estado y las guerrillas. Específicamente, el modelo desestimó el hecho de que el solo reconocimiento de los factores objetivos no era suficiente para comprender y remediar la totalidad de las problemáticas del conflicto armado interno.

Además, en la ejecución del modelo voluntarista, el gobierno reconoció las causas objetivas del conflicto armado, pero se negó a explorar la responsabilidad de las Fuerzas Armadas del Estado. La aceptación de los errores pasados y el esfuerzo de corregir las condiciones que fomentaban la violencia no implicaban la persecución de los funcionarios que habían perpetrado violaciones de derechos humanos. ${ }^{5}$ Consecuentemente, no

5 Patrice MacSherry y Raúl Molina Mejía (1999) narran cómo en América Latina quedaron 
hubo una condena por los actos de terror perpetrados por el aparato estatal. Por ejemplo, nunca se investigó la responsabilidad del gobierno de Julio César Turbay por el desarrollo de "una política represiva orientada por el Estatuto de Seguridad Nacional, que implicó serias violaciones de los derechos humanos" (Fernández, García-Durán y Sarmiento, 2004, p. 12). Así, se perpetuó la sombra del terrorismo de Estado y se mantuvieron en la impunidad los actos violentos ejecutados por el gobierno (McSherry y Molina, 1999).

Aunque, desde su posesión como Presidente de la República, Betancur criticó "algunos elementos represivos del gobierno anterior, [y] planteó la necesidad de crear condiciones para superar situaciones de injusticia, tales como el hambre, el desempleo, el analfabetismo, etc." (Arias, 2008, p. 12), no formuló políticas concretas que investigaran la responsabilidad penal de los funcionarios del Estado por las violaciones de derechos humanos. La construcción de paz se concibió como una especie de borrón y cuenta nueva que intentaba enterrar la historia y dejar en el pasado las heridas causadas por ambos actores durante el conflicto armado. Por esta razón, es posible colegir que el modelo voluntarista carecía de una visión dualista de responsabilidad, lo que de cierta forma afectó la posibilidad de crear estructuras de confianza que facilitaran la estabilidad de los acuerdos de paz desarrollados durante el período.

\subsection{La amnistía y el indulto como herramienta de presión}

El modelo voluntarista plantea algunos cambios a las políticas promulgadas por los gobiernos anteriores. Al menos desde el punto de vista del derecho a la justicia, dos fueron las leyes que se promulgaron durante el gobierno de Betancur que regularon y delimitaron la legalidad de la concesión de amnistías e indultos. Por medio de la Ley 35 de 1982, el Congreso de la República declaró una amnistía general para los delitos políticos y conexos. ${ }^{6}$ Esta ley establecía de manera expresa que los homicidios fuera

impunes aquellos funcionarios del Estado que de manera sistemática diseñaron tácticas de violencia para reprimir a los sectores de la oposición con el fin de perpetuarse en el poder.

6 La ley comprendía delitos políticos como aquellos "tipificados en el Código Penal como rebelión, sedición o asonada y los conexos con ellos por haber sido cometidos para facilitarlos, procurarlos, consumarlos u ocultarlos" (art. $2^{\circ}$ ). 
de combate no quedaban amparados por la amnistía "si fueron cometidos con sevicia o colocando a la víctima en situación de indefensión o inferioridad, o aprovechándose de esa situación" (art. 3). Además, la Ley 49 de 1985 autorizó al Presidente para que concediera indultos a los condenados por delitos políticos, dándole la posibilidad de extender esta medida para favorecer a los condenados por delitos conexos.

Navarro Wolff describe cómo la concesión de amnistías e indultos se originó como un medio de presión para lograr la desarticulación de los grupos armados ilegales. Según él, "la amnistía la presentó el gobierno como un acto soberano suyo, sin negociar con nadie. E intentó que ese acto fuera suficiente para obligar a la guerrilla a legalizarse, por efecto de la presión de la opinión pública, a cambio de eso solamente" (Jiménez, 1989, p. 90). La amnistía y el indulto se consagraban como una herramienta política clave del modelo voluntarista, en tanto que se imponían como una especie de perdón, como un acto de contrición por parte del gobierno que reconocía los factores objetivos del conflicto.

Las contradicciones, limitaciones y deficiencias del modelo de paz del gobierno de Betancur se evidencian de manera rotunda si se analiza críticamente cómo se dio la efectiva implementación de las leyes de amnistía e indulto citadas. Primero, no se contempló la creación de un marco jurídico que también permitiera evaluar la responsabilidad de los miembros de la fuerza pública por violaciones de derechos humanos. Segundo, las leyes de amnistía e indulto reflejaban la unilateralidad del modelo voluntarista, en el que el Estado reconocía los factores objetivos del conflicto, pero pasaba por alto la satisfacción de los derechos de las víctimas a la justicia y la necesidad de aclarar la historia.

\subsection{El modelo participativo}

El gobierno de Barco se apartó del modelo voluntarista y se enfocó en los aspectos políticos del conflicto. Su administración buscó la desmovilización de los grupos guerrilleros a través de la creación de una plataforma política que permitiera su participación en la discusión democrática. Así, intentó negociar con los grupos insurgentes la organización del poder político para permitir su participación e incentivar la dejación de las armas. En enero de 1989, el gobierno firmó un primer compromiso con el M-19 
para lograr el desarme, desmovilización y reincorporación a la vida civil de este grupo armado (Grabe, 2004; Flórez y Valenzuela, 1996). Del acuerdo nació el Pacto Político por la Paz y la Democracia y "el gobierno, amparado en una norma de Estado de sitio y la Ley de Indulto, accedió a la suspensión de las órdenes de captura para que los principales dirigentes del M-19 pudiesen viajar a Bogotá a desempantanar el proceso de desmovilización y desarrollo político de la Alianza Democrática M-19 (AD M-19)" (Grabe, 2004, p. 43).

Al permitirse la participación política y la consolidación de procesos más democráticos, el M-19 atisbó una ventana para la negociación. Se propuso entonces la dejación de las armas a cambio de garantías políticas que permitieran la participación de los grupos al margen de la ley. No obstante, el modelo participativo no tenía como fin primordial la solución al conflicto armado.

En el fondo, el objetivo principal no era negociar una solución al conflicto armado, sino legitimar el Estado y deslegitimar la guerrilla. Es decir, para Barco podía haber negociaciones, pero ya no entre dos partes, sino entre un Estado que conscientemente representaba a la ciudadanía y unos grupos guerrilleros que cada vez eran menos legítimos, pero que podrían aspirar a participar en la vida política del país. La estrategia se resumió en el lema de "Mano tendida; pulso firme" (Chernick, 1996, p. 5).

A pesar de la intención de legitimar al Estado, el modelo de Barco tampoco contempló la necesidad de aclarar la responsabilidad del Estado por las violaciones de derechos humanos pasadas. Como lo retrata Chernick, la estrategia giraba en torno a la deslegitimación de los grupos subversivos.

\subsection{La amnistía y el indulto para la política}

Bajo la administración de Barco, el Congreso de la República promulgó la Ley 77 de 1989, que autorizó al Presidente para conceder indulto a quienes hubieran cometido delitos políticos antes de que la ley entrara en vigencia. Por medio del Decreto 206 de 1990, el gobierno extendió la medida a aquellos combatientes del M-19 que participaron en el acuerdo de paz que se firmó en marzo de 1990. No obstante, para otorgar el indulto, era necesaria "la demostración definitiva de voluntad de reincorporación 
a la vida civil [por] parte de la respectiva organización rebelde y por sus miembros [y] la dejación de las armas en los términos de la política de reconciliación" (art. 5\%). ${ }^{7}$

Como en el modelo voluntarista, del articulado citado es posible concluir que la amnistía y el indulto también se concebían como una herramienta de presión para lograr la desmovilización de los grupos armados. Además, nuevamente se evidencia que la responsabilidad del Estado por violaciones de derechos humanos no hace parte de los temas de negociación.

\subsection{Lecciones de los modelos}

El hecho de que no se haya considerado la amnistía o indulto para los militares en ambos modelos no significa que no se cometieran graves violaciones de derechos humanos por parte del Estado durante las décadas de los ochenta y noventa. Según la Asociación de Familiares de Detenidos Desaparecidos (2004),

se institucionalizaron las desapariciones forzadas, las ejecuciones sumarias en Colombia. Se recrudeció el aniquilamiento de la oposición política y social de forma masiva y sistemática, produciéndose un doble proceso en el que mientras disminuía la represión de los grupos alzados en armas por la vía judicial y con ello el número de presos políticos, por el otro lado comenzó el fenómeno de las desapariciones forzadas y asesinatos por motivaciones políticas. Desde entonces se implementaron prácticas de detención de rasgos clandestinos.

Solo a principios de la década de los noventa surgen fuertes críticas a la impunidad de los actos de terror perpetrados por el Estado. ${ }^{8}$ En 1992, el Tribunal Permanente de los Pueblos sobre Impunidad en América Latina solicita formalmente que se investiguen las violaciones de derechos humanos cometidas por el Estado colombiano. ${ }^{9}$ La publicación hizo que

7 Mario Aguilera Peña (2012) hace un análisis detallado de siete grandes eventos de perdón en la historia de Colombia y estudia la evolución del concepto de delito político en el ordenamiento jurídico colombiano.

8 María Luisa Bartolomei (1998) hace un barrido a los graves problemas de impunidad que persisten en diversos países de América Latina.

9 Según el Tribunal Permanente de los Pueblos sobre Impunidad en América Latina (1995), 
se visibilizaran las cicatrices que había dejado el proceso de paz, al sostener que la impunidad de los crímenes atormentaba el presente y el futuro, limitando las posibilidades de consolidación de la democracia colombiana.

La falta de justicia generó una serie de efectos nocivos que hoy en día empiezan a hacer mella en la sociedad en general y, particularmente, en las víctimas. Si bien las medidas de amnistía e indulto posibilitaron la desmovilización y posterior participación política de un grupo guerrillero como el M-19, la no persecución de los responsables de crímenes graves (tanto del Estado como de los grupos insurgentes) dejó vacíos en la satisfacción de los derechos de las víctimas a la verdad, la justicia y la reparación. Adicionalmente, a pesar de los elementos positivos de los modelos discutidos, ante los actuales compromisos internacionales adquiridos por el gobierno colombiano, las posibilidades de que en el proceso de paz que se lleva a cabo en La Habana se firme un acuerdo semejante son poco probables, en tanto que le abrirían la puerta a las diferentes instancias internacionales.

Del estudio de los modelos mencionados, es posible concluir que la estrategia pasada de dejar impunes las graves violaciones perpetradas por el Estado no es adecuada, en tanto que no solo incrementa la posibilidad de una futura inestabilidad en el período del posconflicto, sino que también, como se evidenciará, va en contra de las responsabilidades internacionales del Estado colombiano. Como consecuencia, en un escenario de conflicto armado interno como el colombiano, en el cual el Estado ha tenido un papel muy importante, los debates sobre la justicia no deben ser relegados a la periferia de la mesa de negociación.

\section{Retos jurídicos frente a las víctimas. Especial referencia al derecho a la justicia}

El actual proceso de paz se enfrenta a un escenario radicalmente diferente al de las negociaciones pasadas. Esto se debe principalmente a la evolución y el protagonismo que tienen las víctimas, a quienes se les debe garantizar un mínimo de derechos. En Colombia, se han dictado desde

en Colombia "se adaptó de una manera más sutil y por lo mismo más profunda, a la ideología de la Seguridad Nacional, razón por la cual hoy día conserva niveles escandalosos de terrorismo de Estado". 
el año 2005 una serie de normas que se han denominado de justicia transicional', ${ }^{10}$ por medio de las cuales se pretende crear un ambiente que facilite la desmovilización de los grupos armados ilegales y, a la vez, se garantice la satisfacción de los derechos de las víctimas. Desde entonces, el término justicia transicional ha sido ampliamente utilizado en nuestro contexto actual. Normas como la Ley 795 de 2005 o Ley de Justicia y Paz introducen por primera vez en nuestro ordenamiento jurídico este concepto (Orjuela y Lozano, 2012). Cabe preguntarse, entonces, ¿qué es la justicia transicional?

Angelika Rettberg (2005) define la justicia transicional como "el tipo de arreglos judiciales y extrajudiciales que facilitan y permiten la transición de un régimen autoritario a una democracia o de una situación de guerra a una de paz". Así, la justicia transicional es un mecanismo por medio del cual se puede lograr la construcción de paz. Este modelo especial de justicia es perfectamente aplicable en situaciones de conflicto vigente. La justicia transicional no está ligada únicamente a la aplicación de una justicia que facilite el posconflicto o que permita el establecimiento de regímenes democráticos o incluyentes, en tanto que también puede ser usada en transiciones de procesos de paz aun cuando exista un conflicto en curso (Ambos, 2008, p. 27).

Ahora bien, de acuerdo con la doctrina, los mecanismos de justicia transicional deben velar por la protección de los derechos de las víctimas a la verdad, la justicia y la reparación. ${ }^{11}$ Como consecuencia, lo que se pretende es que el Estado investigue y sancione a los culpables de las graves violaciones de derechos humanos (Huber, 2007, p. 50).

Adicionalmente, debe señalarse que no puede limitarse el término de justicia a un modelo de carácter retributivo. Dentro de la justicia transicional también tienen cabida acciones no judiciales dirigidas a esclarecer la verdad de lo sucedido, a construir la memoria colectiva y a crear mecanismos de reparación (Rincón, 2010, p. 26). Las acciones de esclarecimiento de la

10 Las principales normas sobre justicia transicional en Colombia son la Ley 795 de 2005, la Ley 1448 de 2011 y el Acto Legislativo 1 de 2012.

11 Ha de advertirse que estos derechos no se originan únicamente en períodos de justicia transicional, sino que son derechos que deben ser garantizados por el Estado en todo momento. No obstante, para efectos de la aplicación de normas transicionales, los derechos en cuestión adquieren una especial connotación (Rincón, 2010, p. 25). 
verdad y de construcción de la memoria colectiva están destinadas a garantizar el derecho de las víctimas y de la sociedad a conocer la situación que dio lugar a la violación de derechos humanos. Por su parte, la reparación hace referencia a un modelo de reparación integral, que incluye conceptos no solo de restitución e indemnización, sino también otras medidas, tales como la satisfacción, la rehabilitación y las garantías de no repetición. ${ }^{12}$

\subsection{Implicaciones del Marco Jurídico para la Paz frente a los derechos de las víctimas}

Mediante el Acto Legislativo 1 de 2012, se reformó la Constitución y se estableció el Marco Jurídico para la Paz. Dicho acto autorizó la creación de mecanismos de justicia transicional ante un eventual acuerdo de paz. A pesar de la importancia de la iniciativa, el Marco Jurídico para la Paz ha sido objeto de críticas no solo por defensores de los derechos humanos, sino también por diversos académicos y organizaciones internacionales. En particular, existe una creciente preocupación de que se abra la puerta legal al otorgamiento de amnistías e indultos para los autores de delitos de gran connotación, como lo son las violaciones al derecho internacional humanitario, lesa humanidad y genocidio (Comisión Colombiana de Juristas, 2013). Por ejemplo, Gustavo Gallón argumenta: “En aras de facilitar negociaciones de paz, [el Marco Jurídico para la Paz] autoriza al gobierno a conceder amnistías encubiertas para graves violaciones de derechos humanos y del derecho humanitario" (2011).

Otro sector, principalmente representado por el Fiscal General de la Nación, considera que el Acto Legislativo 1 de 2012 no afecta ni viola los derechos de las víctimas. Esta facción defiende que lo que se pretende aplicar es un modelo de justicia transicional que favorezca las iniciativas para la paz. Bajo este raciocinio, sostiene que el uso de medidas de selección y priorización de las investigaciones penales es útil en tanto que permite que el Estado centre sus esfuerzos en la identificación y sanción de los máximos responsables.

12 Corte Interamericana de Derechos Humanos, en la sentencia Masacre de Santo Domingo vs. Colombia, Serie C No 259, 30 de noviembre de 2012. 
Teniendo en cuenta la importancia de la justicia, resulta preocupante que en el Marco Jurídico para la Paz se prescriba que se "garantizarán en el mayor nivel posible los derechos de las víctimas a la verdad, la justicia y la reparación". La ambigüedad en la redacción del Acto Legislativo parece indicar que se limitaría la protección de los derechos de las víctimas. Específicamente, no queda claro cuál es el contenido real del mayor nivel posible, y si dicha posibilidad se predica en relación con el Estado, con la investigación, con los recursos económicos o con otro elemento concreto.

Así mismo, aunque el Acto Legislativo 1 de 2012 contempla la creación de mecanismos efectivos que garanticen los derechos de las víctimas, inquieta el alcance que el Estado colombiano le está dando a la futura Comisión de la Verdad. El Marco Jurídico para la Paz establece que "el mandato de la Comisión podrá incluir la formulación de recomendaciones para la aplicación de instrumentos de justicia transicional, incluyendo la aplicación de criterios de selección". Nuevamente, persiste una imprecisión en la redacción, ya que no se especifica cómo se implementarían los criterios de selección, factor que podría opacar la transparencia de la búsqueda de la verdad.

El caso sudafricano es un referente para analizar el apartado en cuestión. En Sudáfrica, se creó la Comisión de Verdad y Reparación como un organismo para garantizar el derecho a la verdad. Por medio de audiencias públicas, la Comisión propendió por el esclarecimiento de la verdad a las víctimas. En ese entonces, el gobierno sudafricano decidió otorgar amnistías a quienes contaran la verdad sin importar la gravedad de la confesión.

La política implementada por el gobierno sudafricano puede ser vista de dos formas. La medida es positiva en el entendido de que la verdad y la reconciliación fueron los objetivos que primaron en el proceso de construcción de paz. No obstante, a su vez es negativa en la medida en que hay quienes advierten que una verdad sin justicia no conlleva a una adecuada reparación y, por ende, reconciliación (Comisión Colombiana de Juristas, 2007, p. 8). Por consiguiente, es menester discutir cómo conciliar las dificultades que se presentan en el caso sudafricano.

Primero, la verdad no lleva necesariamente a la reconciliación como una consecuencia automática. Muchas veces la verdad puede llegar a abrir más heridas que a cerrarlas, sin embargo, no puede olvidarse que la reconciliación es una construcción que no se consolida de un momento a 
otro, sino que debe estar acompañada por un proceso que sea percibido por las víctimas como legítimo. Es decir, la reconciliación debe erradicar o apaciguar la voluntad de buscar la venganza por medios privados. Por lo tanto, se requiere de un proceso pedagógico e institucional que impulse a la sociedad a abandonar la violencia como forma de retribución.

Segundo, el caso sudafricano demuestra el compromiso máximo de la sociedad y de los victimarios en la construcción de paz. Es un compromiso de la sociedad en la medida en que esta debe aceptar la decisión de poner punto final al conflicto armado sin que ello implique el consenso de todos sus integrantes y la satisfacción de cada una de las demandas sociales. Fundamentalmente, la reconciliación requiere que se dé prioridad a la paz para poder dejar de lado la venganza o el odio. Además, es un compromiso por parte de los victimarios en el entendido que deben estar dispuestos a contar todo lo sucedido sin llegar a verdades a medias o verdades mal contadas. Por consiguiente, el caso sudafricano revela la importancia de institucionalizar un proceso acompañado, respetuoso y comprometido para conocer las violaciones ocurridas durante el conflicto.

Del caso sudafricano también pueden extraerse aspectos para no aplicar. Por ejemplo, el otorgamiento de amnistías automáticas y el no juzgamiento en ninguno de los casos deja un sinsabor en las víctimas. El proceso de verdad, justicia y reparación debe estar acompañado de cada uno de los aspectos antes mencionados y no suprimir por completo ninguno de ellos. Es decir, si bien puede reducirse la justicia o disminuir la reparación, no es posible sacrificar estos dos principios por completo con el único fin de encontrar la verdad.

Ahora bien, volviendo a la discusión sobre el Marco Jurídico para la Paz, otra cuestión que llama la atención es lo relativo a la reparación. Si bien en este instrumento no se hizo mención sobre el carácter de esta, es claro que deben tenerse en cuenta normas como la Ley de Víctimas y las decisiones de la Corte Interamericana, ${ }^{13}$ las cuales establecen el carácter de reparación integral. Consecuentemente, no se debe limitar la reparación a la sanción de los culpables, en tanto que el Estado debe crear mecanismos extrajudiciales que amplíen la protección a las víctimas (Acto Legislativo 1 del 31 de julio de 2012, párrafo 2 del artículo transitorio 66).

13 Ver: Corte Interamericana de Derechos Humanos. Barrios Altos vs. Perú, Cesti Hurtado vs. Perú, Villagrán Morales vs. Guatemala, entre otros. 


\subsection{La satisfacción al derecho a la justicia frente al Marco Jurídico para la Paz y las obligaciones internacionales}

Aunque el tema de este acápite se relaciona estrechamente con el anterior, se ha decidido tratar por aparte, porque no solo guarda relación con la justicia transicional, sino que también tiene que ver con la responsabilidad internacional, ya sea del Estado o de los individuos, por la vía de la Corte Interamericana de Derechos Humanos o la Corte Penal Internacional, respectivamente.

El Acto Legislativo 1 de 2012 establece unos criterios que han generado bastante controversia, toda vez que señala:

Tanto los criterios de priorización como los de selección son inherentes a los instrumentos de justicia transicional. El Fiscal General de la Nación determinará criterios de priorización para el ejercicio de la acción penal. Sin perjuicio del deber general del Estado de investigar y sancionar las graves violaciones a los derechos humanos y al derecho internacional humanitario, en el marco de la justicia transicional, el Congreso de la República, por iniciativa del gobierno nacional, podrá mediante ley estatutaria determinar los criterios de selección que permitan centrar los esfuerzos en la investigación penal de los máximos responsables de todos los delitos que adquieran la connotación de crímenes de lesa humanidad, genocidio o crímenes de guerra cometidos de manera sistemática; establecer los casos, requisitos y condiciones en los que procedería la suspensión de la ejecución de la pena; establecer los casos en los que proceda la aplicación de sanciones extrajudiciales, de penas alternativas, o de modalidades especiales de ejecución y cumplimiento de la pena; y autorizar la renuncia condicionada a la persecución penal de todos los casos no seleccionados. La ley estatutaria tendrá en cuenta la gravedad y representatividad de los casos para determinar los criterios de selección (Acto Legislativo 1 del 31 de julio de 2012, párrafo 4 del artículo transitorio 66).

Frente a este tema, quienes se oponen al esquema de selección y priorización consideran que este trae fuertes inconvenientes por no ceñirse a estándares internacionales de justicia. Algunos sectores manifiestan que, en varias sentencias de la Corte Interamericana de Derechos Humanos, se ha indicado que las graves violaciones a los derechos humanos no pueden ser 
objeto de amnistías e indultos, ni de tratos benévolos. ${ }^{14}$ Por consiguiente, los Estados están encargados de investigar cada uno de los crímenes contra los derechos humanos.

Por ejemplo, la Comisión Colombiana de Juristas (2013) en la demanda de inconstitucionalidad parcial del Acto Legislativo 1 de 2012 argumentó que los Estados no pueden alegar procesos de paz para incumplir con los compromisos internacionales adquiridos. Por lo tanto, al establecer criterios de priorización, se están evadiendo las responsabilidades internacionales del Estado, ya que con esto lo que se pretende es investigar y sancionar a los máximos responsables y dejar sin ningún tipo de sanción a quienes no tengan dicha calidad.

Además, genera aún más incertidumbre que las acciones objeto de investigación sean aquellas que hayan sido cometidas de manera sistemática, siendo que el concepto de sistematicidad es un requisito característico de los delitos de lesa humanidad, y que claramente no puede predicarse de crímenes de guerra o de genocidio. Por consiguiente, lo que debió hacer el legislador fue establecer que la investigación recaería frente a aquellas conductas que se hayan cometido en un contexto especial y bajo unos parámetros concretos, y no exigir su comisión sistemática.

Frente a este aspecto, es importante resaltar que la Corte Constitucional mediante fallo del 28 de agosto de 2013 declaró la exequibilidad condicionada del Acto Legislativo 1 de 2012. La Corte Constitucional indica que para fallar tomó en cuenta la ponderación entre los derechos a la paz y a la reconciliación y los derechos de las víctimas y la garantía de no repetición. Igualmente, establece que, para poder lograr una paz estable y duradera, es posible acudir a la llamada justicia transicional, motivo por el cual se permite el uso de figuras como los criterios de selección y priorización. ${ }^{15}$ Sin embargo, la demanda de inconstitucionalidad solamente fue intentada frente a las expresiones "máximos responsables", "todos los" y "cometidos de manera sistemática", por lo que es posible que existan otras demandas de inconstitucionalidad.

14 Ver: Corte Interamericana de Derechos Humanos. Barrios Altos vs. Perú, Masacre de Mozote y lugares aledaños vs. El Salvador.

15 Ver: Colombia, Corte Constitucional. Sentencia C-579 de 2013, magistrado ponente: José Ignacio Pretelt Chaljub, 28 de agosto de 2013. 
Adicionalmente, cabe señalar que la justicia no se refiere solo a condenas privativas de la libertad. Si bien los Estados deben evitar a toda costa la impunidad, la justicia transicional otorga un cierto margen de maniobra frente a las penas. En este sentido, se encuentran dos tesis preponderantes acerca de la investigación y sanción de organizaciones o grupos criminales por parte del Estado. La primera es la maximalista, según la cual deben investigarse todas las conductas punibles cometidas por los miembros de los grupos armados. En contraposición, se encuentra la tesis minimalista, la cual aboga por el establecimiento de criterios de selección y priorización en la investigación, centrándose en los altos mandos de la organización (Forer y López, 2011). Es claro que el contexto al cual se aplican estas dos tesis es el de la macrocriminalidad, en tanto si se trata de pequeños grupos con una cantidad limitada de conductas punibles no habría discusión alguna frente al tratamiento penal.

Así las cosas, el Estado tiene dos opciones: investigar todas las conductas o seleccionar y priorizar la investigación. Esta última opción es la que establece el Marco Jurídico para la Paz. Al contrario de lo que muchos consideran, esta tesis no es sinónimo de impunidad, en tanto que el Estado no se está eximiendo del cumplimiento de sus deberes de investigación y sanción, sino que centra sus esfuerzos en la búsqueda de una mayor eficiencia.

Los criterios de selección y priorización han sido aceptados por parte de la doctrina, al considerarlos como adecuados cuando existen altas tasas de comisión de graves crímenes. Un sistema judicial, por muy fuerte y consolidado que sea, puede llegar a colapsar si se le impone la tarea de investigar todos los delitos perpetrados. Además, como señalan Bergsmo y Saffon (2011, p. 26), en la mayoría de los casos donde existe un conflicto armado, el poder judicial puede estar destruido o severamente deteriorado, por lo cual no podrá hacer frente a la ola de investigaciones propias de un escenario de posconflicto.

Debe indicarse que en otros países donde se ha decidido aplicar un modelo maximalista este no ha funcionado, ya sea porque el Estado no tiene la capacidad para investigar con la profundidad debida las acciones criminales o porque al momento de la investigación se advierte la complejidad de esclarecer el papel de cada sujeto en la comisión de las conductas punibles. Por ejemplo, Daniel Pastor indica que en Argentina, de 800 expedientes, solo 380 tienen individualizados a los autores y tan solo se han 
emitido 10 condenas. Estos resultados ponen en duda la efectividad del modelo maximalista (Modolell, 2009, p. 82). Así, es posible afirmar que el modelo minimalista no necesariamente trae consigo mayor impunidad. $\mathrm{Al}$ estructurarse de manera rigurosa, este modelo permite sancionar a los máximos responsables y direccionar los esfuerzos del Estado de una forma más eficaz. ${ }^{16}$

Frente al tema en cuestión, la Corte Constitucional en el fallo que avala el Marco Jurídico para la Paz considera que el instrumento es claro en señalar que no podrán dejarse de investigar conductas constitutivas de delitos de lesa humanidad, genocidio y crímenes de guerra. Por esta razón, lo que se pretende es dirigir los esfuerzos a la investigación y sanción de los máximos responsables (Sentencia C-579 de 2013).

Los criterios de selección y priorización deben entenderse siempre de la mano de la aplicación de modelos de justicia transicional, por lo cual es muy acertado que el Marco Jurídico para la Paz así lo manifestara y que la Corte lo reafirmara. El modelo minimalista permitirá avanzar mucho más rápido en la sanción y, por ende, en la satisfacción del derecho a la justicia. Sin embargo, solo tendrá aplicación para la investigación de determinados crímenes y por un tiempo específico, ya que pretender aplicar esta forma de investigación de manera permanente, a futuro y a todos los casos, sería un gran desacierto y una completa violación de las obligaciones internacionales adquiridas por el Estado (Bergsmo y Saffon, 2011, p. 26).

Teniendo en cuenta lo anterior, es importante hacer una referencia a los diálogos de paz en La Habana entre el gobierno colombiano y las FARC. De manera continua las FARC han rechazado el Marco Jurídico para la Paz. La posición del grupo se deriva de su insistencia de "no pagar ni un solo día de cárcel". Ante dichas demandas, cabe preguntarse cómo podría el gobierno armonizar las obligaciones internacionales con la posición de las FARC.

El Estado se encuentra en una situación difícil, en la medida que tiene únicamente dos alternativas para ofrecer a los líderes de las FARC. La primera parte de una realidad, y es que la CPI tiene fuertes indicios de que los líde-

16 Bosnia y Herzegovina se convierte en un gran referente en materia de establecimiento de criterios de selección y priorización, indicando por la vía de la experiencia que deben existir unas reglas claras que permitan establecer cuándo unos casos podrán ser seleccionados para ser investigados y cuándo deberán ser de-seleccionados, igualmente, deberá establecerse claramente cómo operará la priorización (Bergsmo y Saffon, 2011). 
res de esta organización han cometido crímenes de su competencia. Por consiguiente, la ausencia de una sanción interna podría ocasionar que la CPI abriera formalmente una investigación penal. ${ }^{17} \mathrm{La}$ otra posibilidad es la de llevar a cabo una investigación que resulte en penas más benéficas para los implicados en crímenes de gravedad internacional. Dicha opción trae consigo la posibilidad de reducir la sanción bajo el único presupuesto de que la imposición de penas no sea irrisoria. Es decir, procurar una condena que garantice hasta cierto punto los derechos de las víctimas a la justicia.

Es posible dirimir que el Marco Jurídico para la Paz contempla la viabilidad de suspender las penas bajo el cumplimiento de unos requisitos definidos por ley. Por este motivo, se podría pensar que si un jefe de las FARC es procesado y condenado por la comisión de un delito de lesa humanidad, si cumple con los requisitos para la suspensión de la ejecución de la pena, no pagaría un solo día de cárcel. Esta situación no debe entenderse como un incumplimiento a la obligación de investigar y sancionar, y a la garantía del derecho a la justicia, debido a que presupone la existencia de una investigación y una sanción, solo que esta queda suspendida condicionalmente. Sin embargo, al estudiar esta posibilidad legal, la fiscal de la Corte Penal Internacional, en una carta dirigida a la Corte Constitucional - pues se estaba decidiendo la constitucionalidad del Marco Jurídico para la Paz-, manifestó:

Como resultado de este análisis, llegué a la conclusión que una condena que sea grosera o manifiestamente inadecuada, teniendo en cuenta la gravedad de los delitos y la forma de participación del acusado, invalidaría la autenticidad del proceso judicial nacional, aun cuando las etapas previas del proceso hayan sido auténticas.

Debido a que la suspensión de la pena de prisión significa que el acusado no pasa tiempo recluido, quisiera advertirle que se trata de una decisión manifiestamente inadecuada para aquellos individuos que supuestamente albergan la mayor responsabilidad en la comisión de crímenes de guerra y crímenes contra la humanidad. La decisión de suspender la pena de prisión de tales personas sugeriría que el proceso judicial promovido tiene el propósito de sustraer al acusado de su responsabilidad penal, según lo establecido en los artículos 17(2)(c) y 20(3)(a) o, de forma alternativa, que

17 Ver artículo 17 del Estatuto de Roma de la Corte Penal Internacional. 
el proceso judicial fue conducido de manera tal que resulta inconsistente con la intención de someter a la persona a la acción de la justicia, bajo los artículos 17(2)(c) y 20(3)(b). Quisiera resaltar que esta conclusión no se fundamenta en razones de políticas públicas (reglamentación), política o conveniencia, ya que se basa en la interpretación legal más razonable de las disposiciones del Estatuto de Roma, en atención a los factores mencionados anteriormente, que serían estudiados por los jueces de la CPI si tuvieran que fallar sobre el tema. También he tomado en consideración el asunto por su valor potencial de sentar un precedente para los demás casos y situaciones ante la Corte, en el presente y el futuro (Semana, 2013).

En ese sentido, la suspensión de la pena no sería el camino correcto por seguir, en la medida que claramente permitiría la competencia de la CPI para juzgar a quienes han sido cobijados con la medida. Es por ello por lo que deben evaluarse los efectos a futuro de los acuerdos.

Igualmente, la fiscal resalta que entiende que Colombia se encuentra en una situación especial y que, si bien los mecanismos de justicia transicional son adecuados para la construcción de paz, las acciones tomadas deben ser complementadas con una serie de medidas que permitan quitar todo halo de impunidad al proceso adelantado. Se debe promover entonces el reconocimiento de responsabilidad, el acompañamiento de los autores en la búsqueda de la verdad, la desmovilización y el desarme, y la prohibición de participar en la vida pública, que acompañados de penas verdaderas podrían suplir la aparente impunidad (Semana, 2013). Por lo tanto, el Estado debe considerar todos estos aspectos al tomar decisiones con miras a firmar la paz.

Además, debe tenerse en cuenta uno de los parámetros internacionales más importantes frente a la protección de los derechos humanos, como lo son las sentencias de la Corte Interamericana de Derechos Humanos. La CIDH puede interponer sanciones a los Estados cuando estos se han apartado de los deberes consagrados en la Convención Americana sobre Derechos Humanos. Por ejemplo, en las sentencias Barrios Altos vs. Perú y Masacre de Mozote y lugares aledaños vs. El Salvador ${ }^{18}$ (CIDH, 2012b), la Corte hace hincapié en el deber de investigación de los Estados, indicando que bajo

18 Ver: Corte Interamericana de Derechos Humanos. Masacre de Mozote y lugares aledaños vs. El Salvador, 25 de octubre de 2012. 
ninguna circunstancia se acepta que no investiguen a los responsables de graves violaciones a los derechos humanos, como lo son las desapariciones forzadas, ejecuciones extrajudiciales, afectaciones a la integridad personal, torturas y tratos crueles e inhumanos.

Compaginando la posición de la CIDH con la posición de la Fiscalía de la CPI, queda claro que, si bien no es necesario perseguir todos los delitos, el Estado sí debe juzgar a los perpetradores de graves violaciones a los derechos humanos. No obstante, dicha opción también implica que la satisfacción de los derechos de las víctimas en relación con los delitos menores debe contar con una protección mucho más amplia del derecho a la verdad y a la reparación.

\section{Conclusiones}

A manera de conclusión, es menester recalcar los aprendizajes que se pueden extraer de la discusión propuesta. Primero, aunque el gobierno nacional tenga la potestad de negociar con los grupos armados al margen de la ley, su libertad no es absoluta. El otorgamiento de amnistías e indultos está fuertemente limitado por las obligaciones internacionales del Estado colombiano.

Cabe recordar que la CPI es competente de manera subsidiaria para juzgar a individuos de nacionalidad colombiana por los crímenes de guerra, genocidio y de lesa humanidad. ${ }^{19}$ Por lo tanto, el gobierno debe evitar que en las negociaciones con las FARC se firme una carta blanca que consagre la impunidad de los perpetradores de delitos de gravedad internacional. De lo contrario, se abrirían las puertas para la intervención de la CPI.

Segundo y de mayor relevancia es el hecho de que las demandas de justicia que ordena la CPI no son un impedimento para la paz. En general, del estudio de las negociaciones de paz de las décadas de los años ochenta y noventa, se dirime que los requisitos de la CPI son importantes en la medida que fomentan un debate esencial para la estabilidad de los futuros acuerdos de paz. En suma, los derechos de las víctimas a la verdad, la justicia y la reparación, no pueden ser desconocidos bajo ningún punto de vista.

19 La competencia de la CPI para juzgar crímenes de genocidio y lesa humanidad va desde 2002 y desde 2009 para los de guerra. 
Este imperativo no solo se deriva de las obligaciones internacionales del Estado colombiano, sino también de los aprendizajes pasados, los cuales evidencian el error de relegar la justicia para lograr la paz.

\section{Referencias}

Aguilera, M. P. (2012). Refundemos la nación: perdonemos a delincuentes políticos y comunes. Análisis Político, 75, 5-40.

Ambos, K. (2008). El marco jurídico de la justicia de transición. En Ambos, Malarino y Elsner (Eds.), Justicia de transición. Informes de América Latina, Alemania, Italia y España (pp. 23-129). Montevideo: Konrad-Adenauer-Stiftung.

Arias, G. I. (2008). Una mirada atrás: procesos de paz dispositivos de negociación del gobierno colombiano. Working Papers, 4, Fundación Ideas para la Paz, s/p. Asociación de Familiares de Detenidos Desaparecidos (Asfaddes). (2004). Colombia, veinte años de historia y lucha. Donostia: Tercera Prensa.

Bartolomei, M. L. (1998). Las consecuencias de la impunidad en la cultura jurídica, política y social de la Argentina. En Plataforma Argentina contra la Impunidad Barcelona (Ed.), Contra la impunidad en defensa de los derechos humanos (pp. 193-212). Barcelona: Icaria Editorial.

Bergsmo, M., \& Saffon, M. (2011). Enfrentando una fila de atrocidades pasadas. ¿Cómo seleccionar y priorizar casos de crímenes internacionales nucleares? En K. Ambos (Coord.), Selección y priorización como estrategia de persecución en los casos de crímenes internacionales (pp. 23-112). Bogotá D.C.: GIZ-ProFis.

Brandt, P., Mason, D., Gurses, M., Petrovsky, N., E Dagmar R. (2008). When and how the fighting stops: explaining the duration and outcome of civil wars. Defence and Peace Economics, 19(6), 415-434.

Calvo, H. O. (2008). Colombia, laboratorio de embrujos. Madrid: Foca Investigación. Campbell, J. (1976). Succesfull negotiation. Princeton: Princeton University Press.

Comisión Colombiana de Juristas. (2007). Verdad, justicia y reparación. Algunas preguntas y respuestas. Bogotá: Comisión Colombiana de Juristas.

Comisión Colombiana de Juristas. (2013). Intervención de la CCJ en la audiencia pública sobre la inconstitucionalidad del 'Marco Jurídico para la Paz'. Recuperado de http://www.coljuristas.org/

Chernick, M. W. (1996). Aprender del pasado: breve historia de los procesos de paz en Colombia (1982-1996). Colombia Internacional, Edición Especial: Seminario sobre Procesos de Negociación y Paz, 36, 4-8. 
Fernández, C., García-Durán, M., E Sarmiento, F. (2004). Movilización por la paz en Colombia: 1978-2002. En Alternativas a la guerra: iniciativas y procesos de paz en Colombia. Bogotá: Accord.

Flórez, E., E Valenzuela, P. (1996). De la oposición armada al frustrado intento de alternativa democrática en Colombia. Colombia Internacional, 36, 31-40.

Forer, A., E López, C. (2011). Selección y priorización de casos como estrategia de investigación y persecución penal en la justicia transicional en Colombia. En K. Ambos (Coord.), Selección y priorización como estrategia de persecución en los casos de crimenes internacionales (pp. 229-253). Bogotá D.C.: GIZ-ProFis.

Gallón, G. (30 de noviembre de 2011). Un marco jurídico para renunciar a la justicia. El Espectador. Recuperado de http://www.elespectador.com/impreso/ opinion/columna-314331-un-marco-juridico-renunciar-justicia

Grabe, V. (2004). Los procesos de paz 1990-1994. En Alternativas a la guerra: iniciativas y procesos de paz en Colombia. Bogotá: Accord.

Hamber, B. (2003). Does the truth heal? In N. Biggar (Ed.), Burying the past: making peace and doing justice after civil conflict (pp. 155-174). Washington, DC: Georgetown University Press.

Hartzell, C. (2006). Structuring the peace: negotiated settlements and the construction of conflict management institutions. In J. Mernik \& T. D. Mason (Eds.), Conflict prevention and peace-building in post-war societies: sustaining the peace (pp. 31-52). Londres: Routledge.

Huber, F. (2007). La Ley de Justicia y Paz. Desafíos y temas de debate. Bogotá: Fescol. Jiménez, R. R. (1989). Entrevista Antonio Navarro Wolff: M-19: paz y guerra en Colombia. Cuadernos Políticos, 45, 82-104.

Laplante, L. J. (2008). Transitional justice and peace building: diagnosing and addressing the socioeconomic roots of violence through a human rights framework. The International Journal of Transitional Justice, 2, 331-355.

Lira, E. (2010). Trauma, duelo, reparación y memoria. Revista de Estudios Sociales, 36, 14-28.

McSherry, P., E Molina, R. M. (1999). Introduction to 'shadows of state terrorism: impunity in Latin America'. Social Justice, 26(4), 1-12.

Mendeloff, D. (2009). Trauma and vengeance: assessing the psychological and emotional effects of post-conflict justice. Human Rights Quarterly, 31(3), 592623.

Modolell, J. L. (abril, 2008). La justicia de transición en América Latina y Europa, y la jurisprudencia de la Corte Penal Internacional. Informe del VI Seminario del Grupo Latinoamericano de Estudios sobre Derecho Penal Internacional, Valparaíso. 
Orjuela, A., E Lozano, C. (2012). La indeterminación del campo de la justicia transicional en Colombia. Estudios Socio-Jurídicos, 14(1), 255-281.

Pardo, R. (julio, 2002). The prospects for peace in Colombia: lessons from recent experiences. Inter-American Dialogue: Working Paper, 2-11. Recuperado de http://www.thedialogue.org/page.cfm?pageID=32EpubID=893

Porter, E. (2007). Peacebuilding: women in international perspective. Nueva York: Routledge.

Rettberg, A. (2005). Entre el perdón y el paredón: preguntas y dilemas de la justicia transicional. Bogotá: Universidad de los Andes, Facultad de Ciencias Sociales, Facultad de Ciencia Política, CESO.

Rincón, T. (2010). Verdad, justicia y reparación: la justicia de la justicia transicional. Bogotá: Universidad del Rosario.

Carta de la fiscal de la Corte Penal Internacional Fatou Bensouda. Semana. Recuperado de http://www.semana.com/upload/documentos/Documento_354581_20130817

Tribunal Permanente de los Pueblos sobre Impunidad en América Latina. (1995). Recuperado de http://www.sinaltrainal.org/index.php/otras-iniciativas/tribunal-permanente-de-los-pueblos/otros-tpp/84-tribunal-permanente-de-lospueblos-sobre-impunidad-en-america-latina-1

Walter, B. (1999). Designing transitions from civil war: demobilization, democratization, and commitments to peace. International Security, 24(1), 127-155.

\section{Jurisprudencia y normatividad}

Colombia, Congreso de la República. Ley 35 de 1982.

Colombia, Congreso de la República. Ley 49 de 1985.

Colombia, Congreso de la República. Ley 77 de 1989.

Colombia, Congreso de la República. Ley 795 de 2005.

Colombia, Congreso de la República. Ley 1448 de 2011.

Colombia, Congreso de la República. Acto Legislativo 1 de 2012.

Colombia, Corte Constitucional. Sentencia C-579 de 2013, magistrado ponente: José Ignacio Pretelt Chaljub, 28 de agosto de 2013.

Colombia, Presidencia de la República. Decreto 206 de 1990.

Corte Interamericana de Derechos Humanos. Masacres de El Mozote y lugares aledaños vs. El Salvador, Serie C No 252, 25 de octubre de 2012.

Corte Interamericana de Derechos Humanos. Barrios Altos vs. Perú, Serie C No 75, 14 de marzo de 2001. 
Corte Interamericana de Derechos Humanos. Cesti Hurtado vs. Perú, Serie C No 78, 31 de mayo de 2001.

Corte Interamericana de Derechos Humanos. Masacre de Santo Domingo vs. Colombia, Serie C No 259, 30 de noviembre de 2012.

Corte Interamericana de Derechos Humanos. Villagrán Morales y otros vs. Guatemala, Serie C No 77, 26 de mayo de 2001. 